\title{
Extreme microclimate conditions in artificial nests for Endangered African Penguins
}

\author{
BONNIE R. LEI, JONATHAN A. GREEN and LORIEN PICHEGRU
}

\section{Summary}

African Penguins Spheniscus demersus naturally breed in guano burrows which provide shelter from predators and extreme weather conditions. Past guano harvesting has removed this habitat and artificial nests of different types have been deployed, with previous research identifying variable success of these different types. We investigated climatic conditions in two types of artificial nests, and compared them to natural burrows and surface nests for two weeks in the incubation and early chick-rearing phases of the 2012 summer breeding season on Bird Island, Algoa Bay, South Africa. We also compared breeding success since 2009 between some of these nest types. Natural burrows remained the best insulated from extremes of temperature and humidity, with temperatures consistently higher and humidity consistently lower than in exposed nests and the two types of artificial nests. Fibreglass nests retained temperatures $>30^{\circ} \mathrm{C}$, when Spheniscus penguins start being heat-stressed, for the longest periods of time. Sustained high temperatures will induce increased energy expenditure associated with active thermoregulation for birds in these nests. The combination of high temperatures and low humidity could also have contributed to damaging water loss in the eggs and reduced egg survival, as suggested by the consistent lower hatching success in the fibreglass nests. Cement nests had more moderate temperatures than fibreglass nests and higher breeding success, possibly due to superior ventilation. Vegetation cover had no effect on the temperature regime inside fibreglass nests. To maximise conservation efforts for these endangered penguins, additional research should be conducted towards engineering artificial nests that better mimic the conditions of natural burrows.

\section{Introduction}

Penguins evolved from an ancestral species in the subantarctic regions of Australia-New Zealand and the Antarctic Peninsula (Bertelli and Giannini 2005, Baker et al. 2006) and developed efficient morphological and physiological adaptations appropriate for the critically cold land and water temperatures of these areas (Bertelli and Giannini 2005, Dawson and Whittow 2000). While the adaptations for cold conditions of these low latitude Spheniscus penguins remain suited to the waters of cold upwelling currents, they are disadvantageous for hot terrestrial habitats where high temperatures can affect their survival and reproductive success (Luna-Jorquera 1996). Penguins are generally sensitive to heat stress and during extremely high temperatures breeding adults will leave their nests unattended to cool down in the sea (Frost et al. 1976, Seddon and Davis 1989). This tactic can be fatal for the broods of surface nesters, which are exposed not only to overheating, but also to predators that can remove a substantial proportion of a penguin colony's chick production (Yorio and Boesrma 1994, Pichegru 2013). As an adaptation to hot climates, Spheniscus penguins breed in burrows dug in guano, which maintain a constant microclimate, with high relative humidity, buffered temperatures and little exposure to the wind (Frost et al. 1976, Luna-Jorquera 1996). Such natural burrows also provide shelter from heavy rain, which 
increases mortality rates of small chicks raised in surface nests (Randall et al. 1986, Frere et al. 1992, Renner and Davis 2001).

In southern Africa, past guano exploitation reduced suitable burrowing habitat for the African Penguin Spheniscus demersus. Guano harvesting occurred for over more than 150 years, and removed up to $20 \mathrm{~m}$ of guano from some islands (Urquhart and Klages 1996). Consequent reduced breeding success in penguins due to limited habitat availability caused by guano removal contributed to the $90 \%$ decrease observed in African Penguin population size during the $20^{\text {th }}$ century (Frost et al. 1976, Crawford et al. 1995). African Penguins are now 'Endangered' (IUCN 2012) and their population continues to decline due to a number of anthropogenic factors (Kemper 2006, Crawford et al. 2011). This situation has stimulated management institutions to identify the major threats weighing on the species and set objectives to address them (Shaw et al. 2012). The lack of suitable nesting habitat, leading to increased brood mortality during extreme weather events, has been identified as a major problem to be addressed (Shaw et al. 2012). Global climate change is also likely to increase the frequency of extreme weather events such as heat waves or storms (Parmesan et al. 2000).

Conservation efforts have included the provision of artificial nests constructed of materials such as cement, fibreglass plastic and wood at several breeding sites to shelter surface-nesting penguins from extreme weather events and aerial predators (Kemper et al. 2007, Sherley et al. 2012, Pichegru 2013). The provision of artificial nests has proved a highly successful conservation intervention in other threatened bird populations (e.g. Catry et al. 2009, Libois et al. 2012). Among penguins, artificial nests have proved successful in increasing breeding success of Little Penguins Eudyptes minor in New Zealand by decreasing predation (Perriman and Steen 2000) and potentially providing protection from rain (Renner and Davis 2001). However, similar nests deployed in Western Australia had high interior temperatures and actually failed to benefit the same species (Ropert-Coudert et al. 2004). For African Penguins, research has shown that fledging success was better in two types of artificial nests (fibreglass and cement) compared to surface nests, but hatching success was consistently lower in artificial fibreglass nests (Pichegru 2013). Further studies in Namibia and South Africa have also shown that some artificial nests can improve breeding success relative to surface nests (Kemper et al. 2007, Sherley et al. 2012). The causes for this varying success of different artificial nest types remain largely unexplored, although temperatures are known to affect the benefits from artificial nests for other bird species (Ardia et al. 2006, Garcia-Navas et al. 2008, Charter et al. 2010, Catry et al. 2011).

This project aimed to investigate the climatic conditions within different types of artificial nests for African Penguins and compare them to natural burrows and surface nests alongside estimates of hatching and fledging success in some of these nest types. Such information is useful to gauge the effectiveness of artificial nests in increasing penguin productivity and in turn contribute to their optimal design with the ultimate goal of maximising conservation efforts for this endangered species.

\section{Methods}

The study took place during the austral summer month of March 2012 on Bird Island, Algoa Bay, Eastern Cape, South Africa $\left(33^{\circ} 50^{\prime} \mathrm{S}, 26^{\circ} 17^{\prime} \mathrm{E}\right)$. Algoa Bay supports almost half of all African Penguins (Crawford et al. 2011) in an extended breeding season that lasts from January to August (Hockey et al. 2005). Bird Island is grassy and flat without rocks or bushes, and although some natural burrows in guano are present, these represent only c.1\% of the breeding population and most penguins (>90\%) breed in surface nests.

Two types of artificial nests were installed by South African National Parks on Bird Island in 2009 and 2010 (see Pichegru 2013 for details): (1) fibreglass nests, are translucent, $60 \mathrm{~cm}$ long, $40 \mathrm{~cm}$ wide and $30 \mathrm{~cm}$ high, with an opening at one end $25 \mathrm{~cm}$ wide and $28 \mathrm{~cm}$ high, and some holes to allow ventilation, they were half buried in the ground and covered with large stones for shade; (2) nests made from sections of $2 \mathrm{~cm}$-thick cement half pipes $\mathrm{c} .70 \mathrm{~cm}$ long, $30 \mathrm{~cm}$ wide and 
$30 \mathrm{~cm}$ high. Due to the topography of the island, all artificial nests had similar exposure to the sun. In this study we used iButtons (Thermochron iButton model DS1921L-F51, Maxim/Dallas Semiconductor Corp.) to record climatic conditions in the two types of artificial nests, as well as in natural burrows and surface nests for comparison. A total of 37 iButtons were deployed between 6 and 22 March 2012 and data were collected from 32 of them: 12 in fibreglass nests, 11 in cement nests, six in natural burrows and three in different unshaded locations on the island recording conditions experienced in the surrounding surface nests. Date losses were due either to material that got lost and failure to record. All iButtons recorded temperature every to minutes, while humidity was recorded at the same frequency in five fibreglass nests, six cement nests and three natural burrows. For cement nests, one iButton per nest was attached to the inside of the cement pipe using a wooden clamp (Figure $I A-1 B$ ), placed so that it would not be in contact with either the nesting bird or the cement. In fibreglass nests, the iButton was inserted through a ventilation hole so that it extended into the nest (Figure ${ }_{1} \mathrm{C}$ ). A wire was used to secure the iButton in the natural burrows, and positioned away from the breeding bird for faithful recording of nest rather than bird conditions (Figure $\mathrm{ID}$ ). Checks were conducted every other day during the iButton deployment, to ensure the loggers remained securely attached and were not in contact with a nesting penguin if present. In fibreglass nests, the degree of vegetation cover by grass Tetragonia

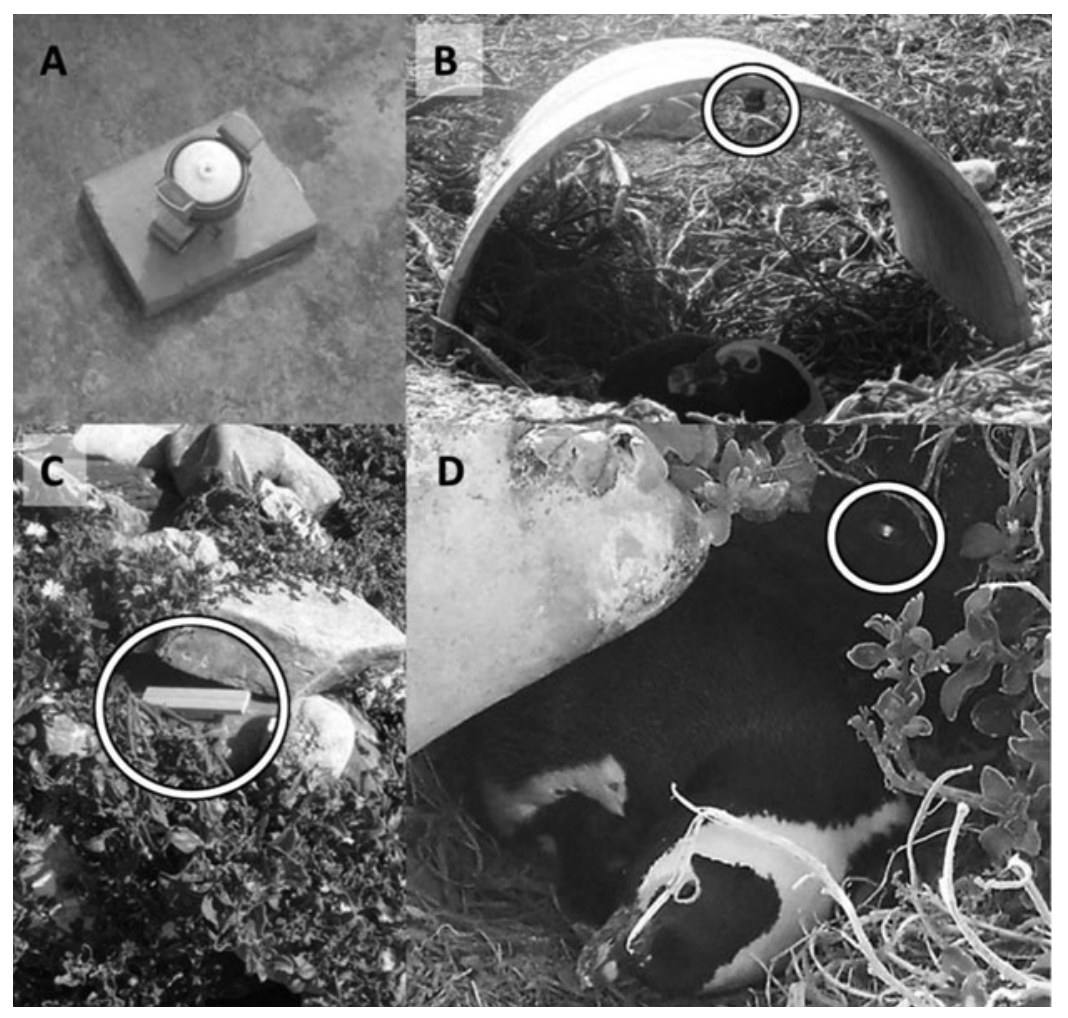

Figure 1. (A) Close up view of iButton attached in a metal clamp and securely glued to the underside of an artificial cement nest to measure interior temperature and humidity. (B) Front view of cement nest, with iButton attached to top (circled) and nesting Spheniscus demersus underneath. (C) Wood and metal clamp device (circled) holding iButton balanced on top of an artificial fibreglass nest partially covered by vegetation. (D) iButton (circled) held by wire and pierced into the upper right side of $S$. demersus natural burrow. 
spp. was recorded and ranked as o indicating no cover, 0.5 indicating partial cover and $\mathrm{I}$ indicating full cover. Nests were assessed for occupancy at the start and end of the deployment period and scored as either occupied (breeding birds present at the start and end of the deployment), partially occupied (breeding birds present at the start or end of the deployment) or unoccupied (no breeding birds present at either the start or end of the deployment). All breeding birds observed were incubating eggs $(56 \%)$ or brooding small chicks $(44 \%)$ during the period of iButton deployment.

Data from the iButtons were downloaded to a laptop computer and analysed using Microsoft Excel and Minitab. For each nest and for each day of the deployment period, we extracted the maximum temperature, the daily temperature amplitude (i.e. the range between minimum and maximum temperature recorded), and the time of day at which the maximum temperature occurred. We also calculated the amount of time for which temperatures exceeded $30^{\circ} \mathrm{C}$ per day. This threshold was selected as it is the temperature at which the closely related Humboldt Penguin S. humboldti become heat stressed (Drent and Stonehouse 1971). For nests where humidity was recorded we calculated minimum humidity, daily humidity amplitude and the time at which the minimum humidity occurred. Preliminary analysis indicated no influence of nest occupancy on any of the temperature or humidity parameters. This was the same whether occupancy was scored conservatively (partially occupied nests classified as 'unoccupied'), liberally (partially occupied nests classified as occupied) or with all three occupancy states incorporated. Thus we did not consider the role of occupancy further in this study. All of these quantities were analysed using General Linear Models which included nest ID nested into nest type, with date and nest type as fixed factors. We were primarily interested in the effect of nest type while inclusion of the other factors accounted for a large proportion of the variability in the data. Tukey post-hoc tests were used to further investigate differences between each nest type. A similar approach was used to test for the effect of cover type in fibreglass nests. In all statistical testing $\alpha=0.05$. Data are presented as the Estimated Marginal Mean \pm SEM from the GLMs.

In parallel, a random sample of $40-150$ nests of each type (surface, fibreglass and concrete) were individually marked and their contents (number of adults, eggs, chicks and their size) were monitored weekly to bi-weekly from January to August since 2009 until failure of the breeding attempt or fledging of the chicks (see details in Pichegru 2013). Natural burrows were not monitored due to the low number of these nests on the island and the sensitivity of the habitat (i.e. risk of collapse of the burrow during nest check). Each breeding attempt in a marked nest was considered independently, as most of the birds were not individually marked and more than one pair may occupy a nest site in a given season. Breeding success was estimated using Mayfield's method (1975) and nest survival probabilities were compared using survival models with the "survreg" function in R v2.12.o (R Development Core Team 2010), which treats the number of days to nest failure as the response variable (details in Sherley et al. 2012, Pichegru 2013). Hatching and fledging success were modelled separately with year and nest type as explanatory variables. Interactions between years and nest types were tested, but not being significant, they were removed from the models.

\section{Results}

Temperatures in all types of nests increased steadily during the morning to a maximum in the middle of the day before declining steadily again in the afternoon (Fig 2A). Maximum temperature occurred at approximately midday in surface and cement nests and significantly later at approximately 13 hoo in natural and fibreglass nests $\left(\mathrm{F}_{(3,496)}=4.3, P<0.001\right)$. Mean daily maximum temperature in exposed nests at the colony surface was $30.7 \pm 0.3{ }^{\circ} \mathrm{C}$, but extreme temperatures in excess of $40^{\circ} \mathrm{C}$ were recorded in exposed (one of three), cement (two of II) and fibreglass (seven of 12 ) nests, but not in natural burrows. The difference in mean maximum temperature between natural burrows and fibreglass nests was nearly $6^{\circ} \mathrm{C}$ (Figure $3 \mathrm{~A}$ ). Mean daily maximum temperature was significantly lower in natural burrows than exposed and both types of artificial nest $\left(\mathrm{F}_{(3,496)}=19.4\right.$, $P<0.001)$. Penguins breeding in surface nests and both types of artificial nest were exposed to mean daily temperature amplitude of $12-13^{\circ} \mathrm{C}$ (Fig $3 \mathrm{~B}$ ). Daily temperature amplitude was 


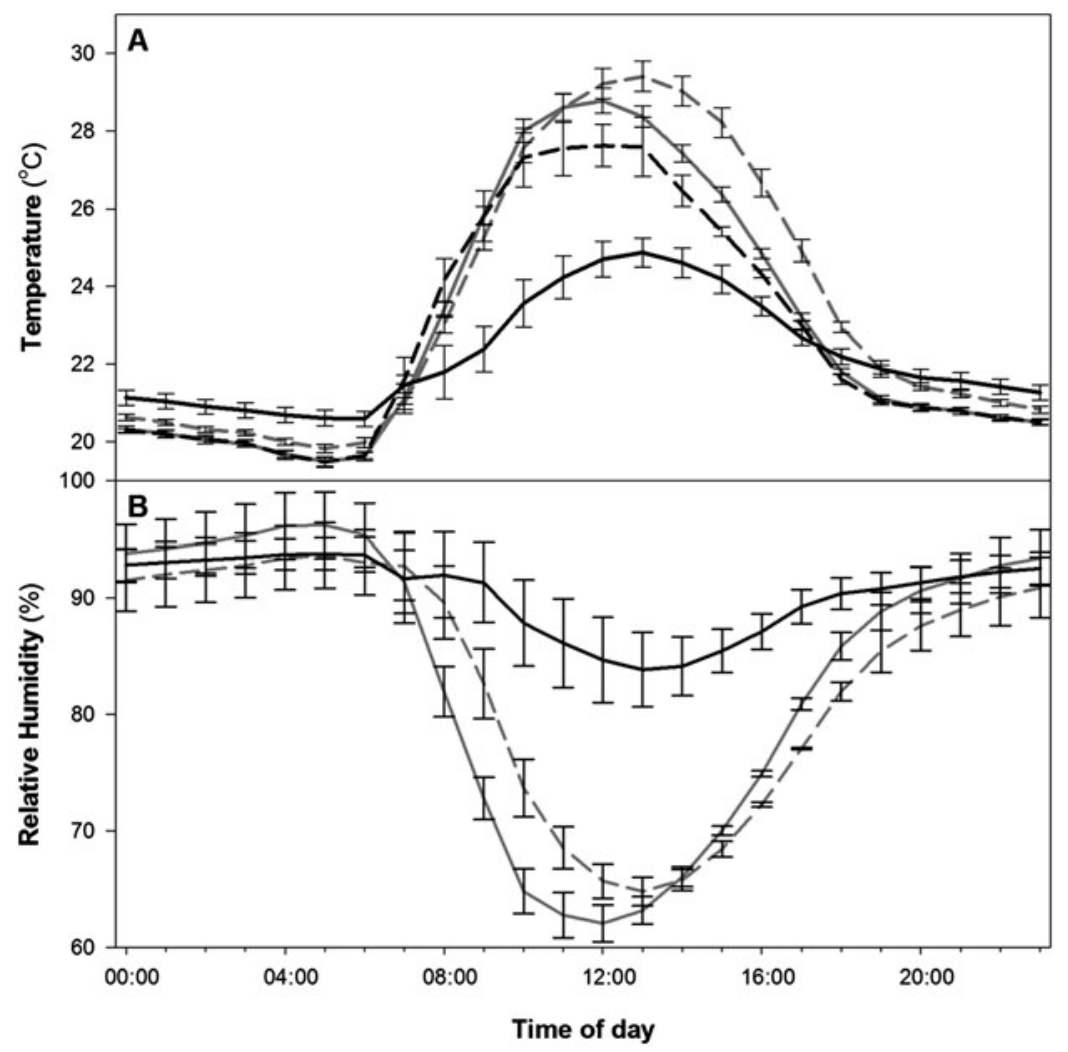

Figure 2. Mean (A) temperature and (B) humidity recorded throughout the day in African Penguin nests on Bird Island, Algoa Bay, South Africa over a 17-day period in March 2012. Recordings were made in natural burrows (solid black lines), exposed surface nests (dashed black lines), cement artificial nests (solid grey lines) and fiberglass artificial nests (dashed grey lines). See text for sample sizes.

significantly lower in natural burrows $\left(\mathrm{F}_{(3,496)}=26.5, \mathrm{P}<0.001\right)$ at around $6^{\circ} \mathrm{C}$ (Figure ${ }_{3} \mathrm{~B}$ ). Finally, while natural burrows rarely exceeded $30^{\circ} \mathrm{C}$ (on average $<10$ min per day), the amount of time with temperatures above $30^{\circ} \mathrm{C}$ was $7.6 \mathrm{x}$ greater in exposed nests, $12.1 \mathrm{x}$ greater in cement nests and $16.3 \mathrm{x}$ greater in fibreglass nests $\left(\mathrm{F}_{(3,496)}=12.1, P<0.001\right.$; Figure $\left.{ }_{3} \mathrm{C}\right)$.

Relative humidity reached a minimum at the same time that temperatures were maximum in each nest type, which was around midday in cement nests, and slightly later around $1_{3} \mathrm{~h}_{3} \mathrm{O}$ in natural burrows and fibreglass nests, though this difference was not statistically significant $\left(\mathrm{F}_{(2,208)}=2.5, P=0.12\right.$; Figure $\left.2 \mathrm{~B}\right)$. Mean daily humidity amplitude was significantly greater in both types of artificial nest than in natural burrows $\left(\mathrm{F}_{(2,208)}=19.9, P<0.001\right.$; Figure $\left.4 \mathrm{~A}\right)$ with a range of over $40 \%$ in cement nests and less than $20 \%$ in natural burrows. Minimum relative humidity was also significantly lower in both types of artificial nest than in natural burrows $\left(\mathrm{F}_{(2,208)}=26.0, P<0.001\right.$; Figure $\left.4 \mathrm{~B}\right)$.

Vegetation cover on fibreglass nests had no effect on mean daily maximum temperature, daily temperature amplitude or the mean daily amount of time greater than $30^{\circ} \mathrm{C}\left(\mathrm{F}_{(2,176)}=0.39,0.27\right.$, o.19; $P=0.69,0.77,0.83$; Figure 5).

Confirming trends observed in Pichegru (2013), hatching success remained consistently lower in fibreglass burrows than in surface nests $\left(Z_{(5,1122)}=5.57, P<0.0001\right)$ and concrete burrows 


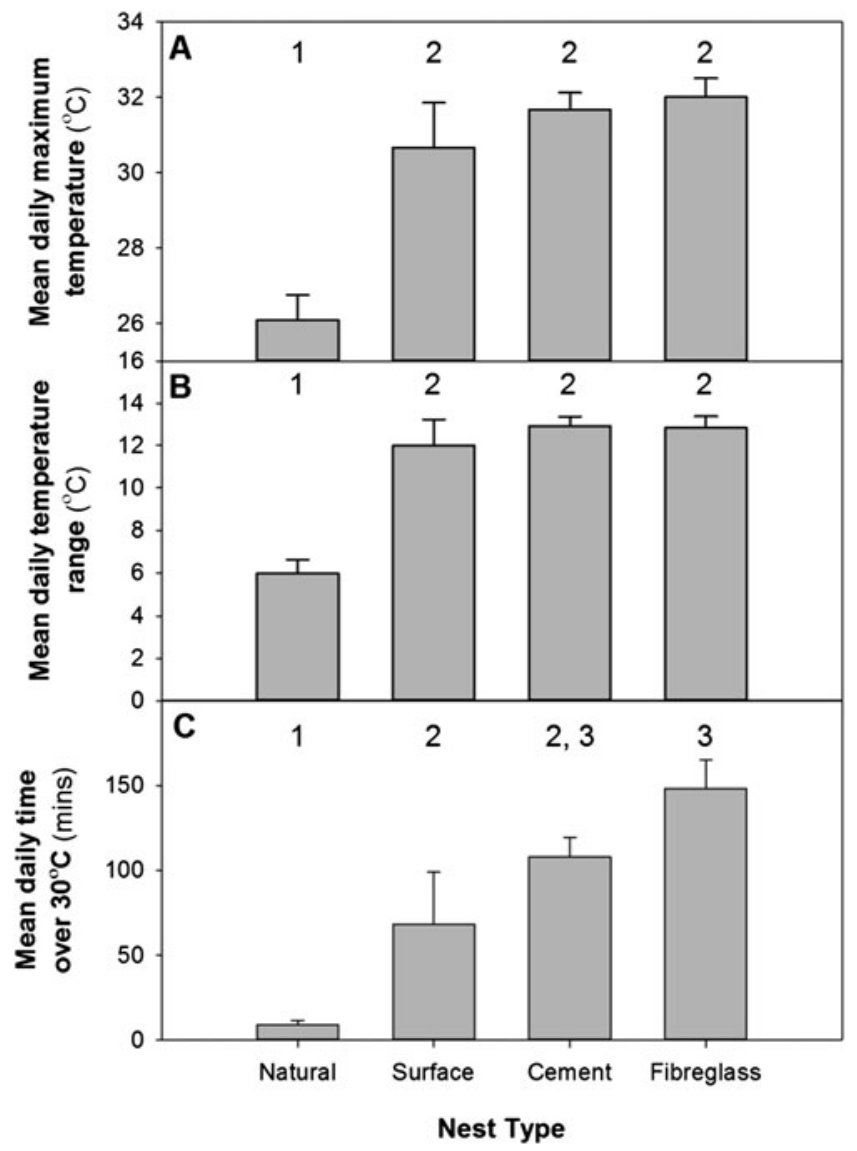

Figure 3. Mean daily (A) maximum temperature, (B) temperature amplitude and (C) the time that temperature exceeded $30^{\circ} \mathrm{C}$ in different types of African Penguin nests on Bird Island, Algoa Bay, South Africa over a 17-day period in March 2012. Columns with the same number above them were not significantly different from each other. See text for sample sizes and test details.

$\left(Z_{(5,1122)}=3.38, P<0.001\right.$, Table 1, 2). In contrast, fledging success was lowest in surface nests $\left(Z_{(5,402)}=-2.71, Z=0.007\right)$ and slightly higher in concrete than in fibreglass burrows $\left(Z_{(5,402)}=2.13\right.$, $P=0.03)$. Fledging success generally showed greater variability between years than hatching success (Table I).

\section{Discussion}

The alarming declining trend of the African Penguin population in South Africa has galvanised management bodies to seek adequate solutions for every identified threat to the species, including the lack of suitable nesting habitat and predation by gulls (Shaw et al. 2012). Different types of artificial nests have been installed at several breeding sites, but recent studies have demonstrated contrasting success between nest types and localities (Kemper et al. 2007, Sherley et al. 2012, Pichegru 2013). Nevertheless, little work has been done to understand the mechanisms underpinning these observations and how these might vary between different types of artificial nests. In this study, investigating climatic conditions alongside reproductive success within artificial and natural nests revealed that current types of artificial nests are actually far from mimicking natural 


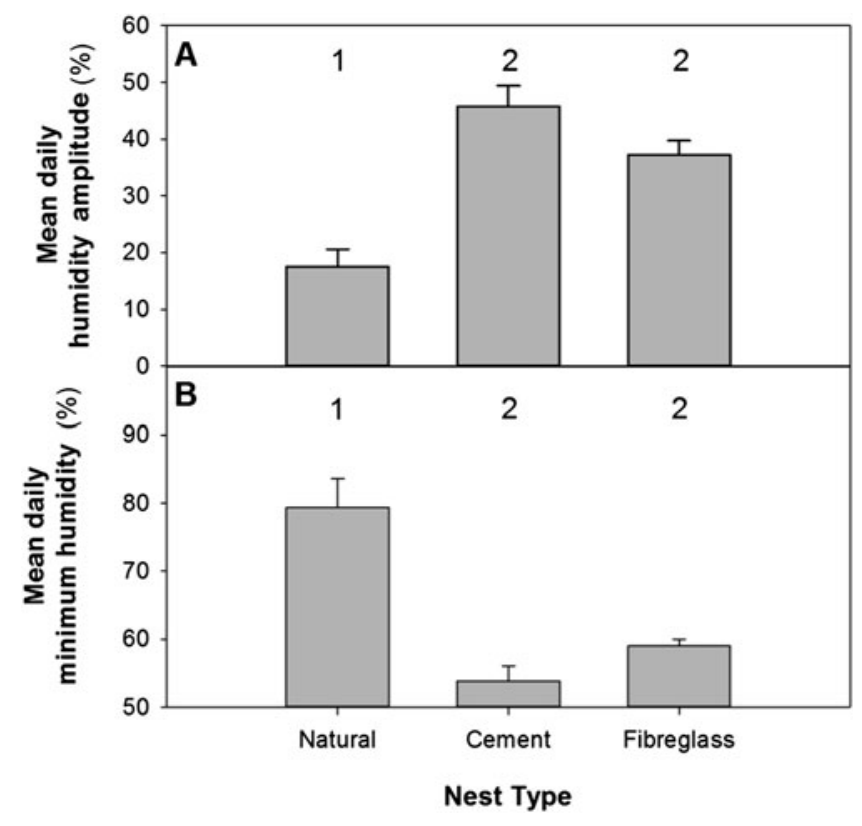

Figure 4. Mean daily (A) humidity amplitude and (B) minimum humidity in different types of African Penguin nests on Bird Island, Algoa Bay, South Africa over a 17-day period in March 2012. Columns with the same number above them were not significantly different from each other. See text for sample sizes and test details.

conditions on Bird Island. Natural burrows provide a seemingly ideal environment for breeding success, as it is insulated from extremes of temperature and with high humidity (Figs. 3 and 4 ). Although success in these nests could not be assessed in this study due to logistical and conservation concerns, previous studies demonstrated higher success of guano burrows over other nest types (e.g. Frere et al. 1992). The guano of these natural burrows absorbs and retains moisture that is collected through precipitation and other processes, resulting in the higher moisture content in the nest interior (Frost et al. 1976). Temperatures inside artificial nests were consistently higher than in natural burrows and remained high for a longer period of time, especially in fibreglass nests. Our study was conducted during incubation and early chick rearing when one adult bird must be present at all times to incubate the egg or brood the chick. At temperatures between 31 and $34^{\circ} \mathrm{C}$, adult Humboldt penguins increased their Field Metabolic Rate (FMR) by $20-40 \%$ due to active thermoregulation (Luna-Jorquera 1996). If we assume that African Penguins also start actively thermoregulating at temperatures above $30^{\circ} \mathrm{C}$ (Drent and Stonehouse 1971), individuals in artificial burrows would have to sustain higher rates of energy expenditure, for periods 12-16 times longer during a day than individuals breeding in natural burrows. Such increased energy expenditure may affect brood survival and the propensity to desert the nest, though further observational studies are required to confirm this.

Our study coincided with the end of the incubation phase for this population and extremely high temperatures may be lethal for embryos. Normal egg temperatures for African Penguins range between 31.9 and $36.0^{\circ} \mathrm{C}$, with a maximum recorded being $38.7^{\circ} \mathrm{C}$ (Burger and Williams 1979). Temperatures $>40^{\circ} \mathrm{C}$ were recorded at times in surface nests and both types of artificial burrows, especially in fibreglass nests. In the absence of ventilation in fibreglass burrows, such high temperatures combined with low humidity levels could have led to excessive and damaging water-loss by the eggs (Yom-Tov et al. 1986) and affected egg survival, which may explained the consistently lower hatching success in these nests (Table 1 ). 


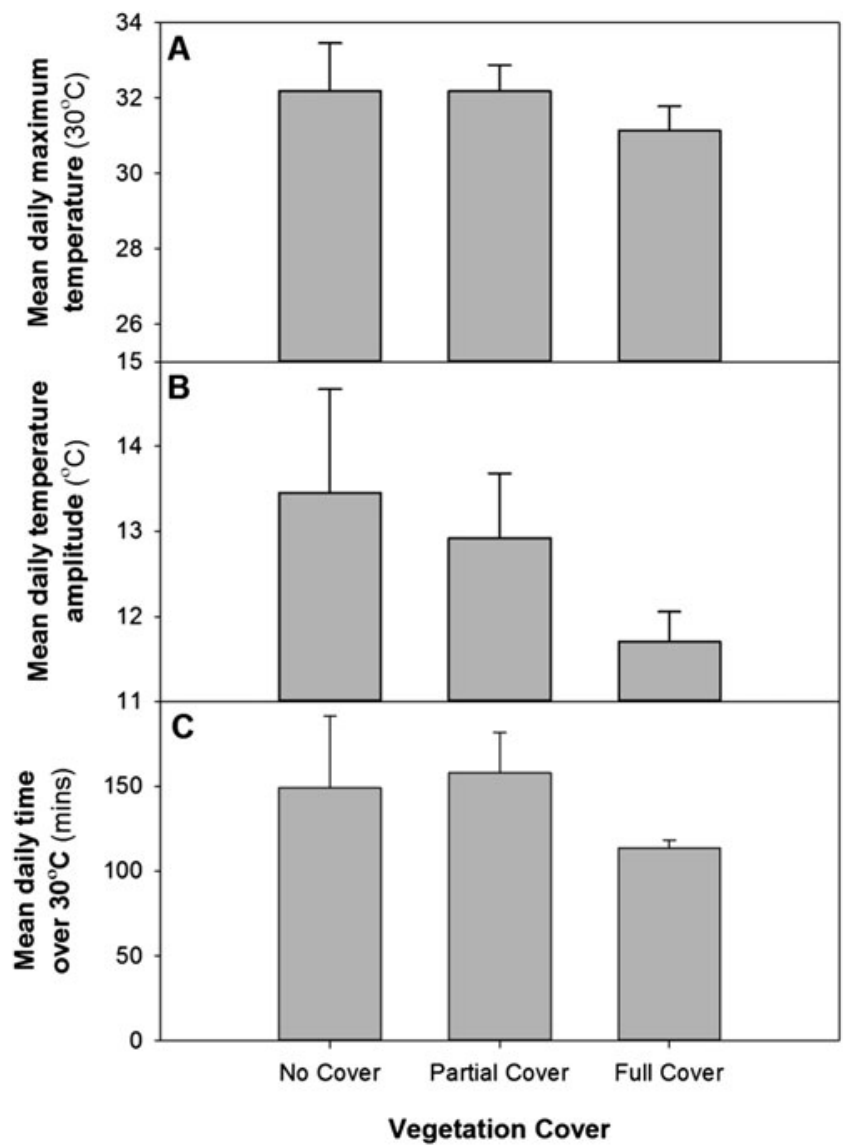

Figure 5. Mean daily (A) maximum temperature, (B) temperature amplitude and (c) time that temperature exceeded $30^{\circ} \mathrm{C}$ in fibreglass artificial African Penguin nests with different levels of vegetation cover on Bird Island, Algoa Bay, South Africa over a 17-day period in March 2012. Columns with the same number above them were not significantly different from each other. See text for sample sizes and test details.

Penguins breeding in surface and artificial nests also experienced daily amplitudes in temperature which were double that of natural burrows (Figure 3). Magellanic Penguin S. magellanicus embryos seem to be able tolerate high variations in temperature without visible impact on their survival (Barrionuevo and Frere 2012), although in their case temperatures varied between 20 and $34^{\circ} \mathrm{C}$, which was lower than the present study. Slight variations in temperatures at incubation are known to affect growth and stress levels in ducklings (Durant et al. 2010), and it might be of interest to assess the effect of nest types on chick growth in African Penguins.

Nevertheless, of the two artificial nest types cement pipes presented the best design so far as heat-stress inducing temperatures were not retained for as long. Importantly, hatching success was higher in the cement as opposed to fibreglass nests (Table I), suggesting that the cement nests provide not only a shelter from predators and/or direct irradiation when compared to surface nests, but also a favourable thermal environment when compared to fibreglass nests. That penguins can withstand the high temperatures and low humidity in cement nests could be explained by better ventilation, as cement nests have large openings at both ends of the pipe while fibreglass nests have only one opening supplemented by smaller ventilation holes. Our iButtons did not 


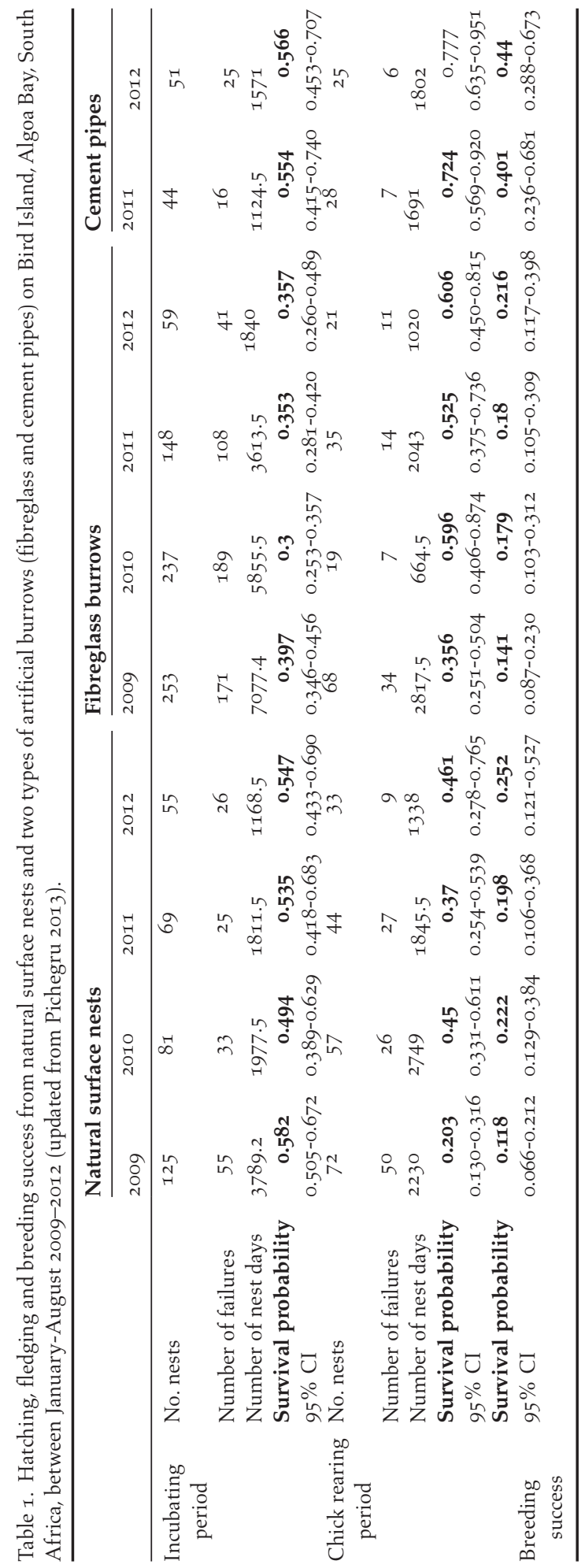


Table 2. Results of survival analyses comparing hatching and fledging success between years (2009-2012) and nest types (surface nests, fibreglass and concrete burrows) (updated from Pichegru 2013).

\begin{tabular}{|c|c|c|c|c|c|c|}
\hline & & Value & SE & $z$ & $P$ & \\
\hline \multirow[t]{6}{*}{ Hatching } & intercept & 3.72 & 0.07 & 52.82 & $<0.0001$ & $* * *$ \\
\hline & Year 2010 & -0.26 & 0.09 & -2.79 & 0.005 & $* *$ \\
\hline & Year 2011 & -0.15 & 0.12 & -1.36 & 0.174 & ns \\
\hline & Year 2012 & -0.11 & 0.13 & -0.83 & 0.405 & ns \\
\hline & Type surface & 0.53 & 0.10 & $5 \cdot 57$ & $<0.0001$ & $* * *$ \\
\hline & Type concrete & 0.59 & 0.18 & 3.38 & 0.0007 & $* * *$ \\
\hline \multirow[t]{6}{*}{ Fledging } & Intercept & $4 \cdot 31$ & 0.14 & 30.76 & $<0.0001$ & $* * *$ \\
\hline & Year 2010 & 0.69 & 0.21 & 3.27 & 0.001 & $* * *$ \\
\hline & Year 2011 & 0.47 & 0.19 & 2.53 & 0.011 & $*$ \\
\hline & Year 2012 & 0.72 & 0.24 & 3.07 & 0.002 & $* *$ \\
\hline & Type surface & -0.43 & 0.16 & -2.71 & 0.007 & ** \\
\hline & Type concrete & 0.69 & 0.32 & 2.13 & 0.033 & $*$ \\
\hline
\end{tabular}

measure effective temperature, which takes into account the combined effects of convective and radiant heat transfer (Bakken 1992), but the greater ventilation and lower humidity in cement nests could facilitate heat loss by the nesting penguins, and result in a lower effective temperature. Further studies assessing the effective temperature, including radiation and particularly ventilation are necessary to understand the mechanisms underpinning the better hatching success of these nests, despite high temperatures.

Nevertheless, cement pipes showed consistent higher fledging success than other nest types, which led to significantly increased penguin productivity. This result highlights the importance of artificial nests in providing shelter for larger chicks against heavy rain and predators. Ideally, artificial nests should provide solutions to all environmental challenges faced by nesting birds and these challenges will vary both within and between species. In African Penguins breeding in Algoa Bay, the environmental challenges change as the breeding season progresses. During incubation at the end of the austral summer in February and March, when we conducted our study, high temperatures are likely to be the primary factor causing low success in exposed nests as parent birds are exposed to heat stress and may abandon their eggs and small chicks. However, during chick-rearing from April to June, rain, storms and predation lead to the death of unguarded chicks. Both artificial nest types appear to provide some shelter from rain, storms and predation such that chick survival is higher than in exposed nests later in the season (Table 1 , Pichegru 2013). However, our findings from this study suggest that fibreglass nests fail to provide adequate protection from the harsh thermal conditions found during incubation and brooding at the start of the breeding season. Cement nests do appear to provide some shelter from direct radiation, yet temperatures are high and humidity low, which may increase thermoregulation cost in penguins breeding in these nests. We suggest therefore that further improvements to the design of cement nests must be made, with for example thicker cement walls which would increase the insulation property of the nest, to better mimic natural burrows and avoid these demanding environmental conditions. Such improved nests may lead to even higher hatching, and hence breeding, success.

While vegetation cover had no effect on internal temperatures for fibreglass nests, our data (Figure 5) suggest that providing shade with natural vegetation or through artificial means is another management option that bears further investigation. A shading effect could be similar to that of orientation of nest boxes, which influenced greatly temperatures in artificial boxes for terrestrial birds (Ardia et al. 2006, Charter et al. 2010, Catry et al. 2011). While it is probably safe to assume similar small benefits of vegetation cover over the longer term on cement nests, further artificial nest materials could also be considered to match the conditions experienced by birds nesting in natural burrows. For example, in Lesser Kestrels Falco naumanni wooden nest boxes had temperatures far in excess of those made of adobe, cement and stone (Catry et al. 2011). As a result, mortality of chicks in wooden boxes was higher during periods of high ambient temperatures, and those that did survive had a lower 
growth rate and poorer body condition at fledging due to the cost of thermoregulation (Catry et al. 2011). For African Penguins in contrast, wood being moisture-absorbent might be more beneficial than fibreglass burrows and has been in use at Robben Island since 2001 (Sherley et al. 2012).

\section{Conclusion}

Sutherland et al. (2004) highlight the importance of making conservation decisions based on evidence and the current study will aid conservation practitioners in southern Africa as they endeavour to make practical interventions to address these threats, in this case by improving the design of artificial nests. Artificial nests for threatened avian populations have proven successful in the past, provided that the design and placement of the nest is adequate to counter the environmental challenges posed to birds (e.g. Perriman and Steen 2000, Catry et al. 2009, 2011, Libois et al. 2012). This study further supports the idea that cement nests may be the better artificial nest option for African Penguins (Pichegru 2013) since they appear to provide some protection from radiation during incubation and from rain and predation during chick-rearing. However they are far from a complete panacea, as temperatures remain unnaturally high and humidity low. Vegetation cover will improve over time and may increase the capacity of these nests to provide adequate shelter. Nevertheless, additional research is necessary towards engineering an artificial nest that can better mimic the conditions of natural burrows, with more buffered temperatures, perhaps through better insulation, and higher relative humidity. Tests of different materials should now be conducted to determine alternative building or lining materials that can maintain higher humidity levels within the nest, while also considering factors such as durability and hygiene (Kemper et al. 2007). It is also important to determine the thermo-neutral zone for African Penguins, in case it differs from Humboldt Penguins. This could be done by studying the thermoregulatory behaviour of penguins to determine when they are heat-stressed. This would be an appropriate indicator, since it is through their behaviour that they can dissipate energy, conserve water, and reduce thermal stress (Lustick 1984, Davenport 1992, Dawson and Whittow 2000).

\section{Acknowledgements}

We wish to thank SANParks for some data collection and assistance with transport and logistics for the field work. During the study, BL was funded by the Weissman International Internship Program, and LP by BirdLife South Africa through "the African Penguin Species Champion" project of the Charl van der Merwe Trust. We also thank Pablo Yorio, Esteban Frere and one anonymous referee for constructive comments on the manuscript.

\section{References}

Ardia, D. R., Perez, J. H. and Clotfelter, E. D. (2006) Nest box orientation affects internal temperature and nest site selection by tree swallows. J. Field Ornithol. 77: 339-344.

Baker, A. J., Pereira, S. L. Haddrath, O. P. and Edge, K. A. (2006) Multiple gene evidence for expansion of extant penguins out of Antarctica due to global cooling. Proc. R. Soc. B 273: 11-17.

Bakken, G. S. (1992) Measurement and application of operative and standard operative temperatures in ecology. Am. Zool. 32: 194-216.

Barrionuevo, M. and Frere, E. (2012) Magellanic penguin (Spheniscus demersus) embryos tolerate high temperature variations and low temperatures during incubation. Waterbirds 35: 485-489.

Bertelli, S., and Giannini, N. P. (2005) A phylogeny of extant penguins (Aves: Sphenisciformes) combining morphology and mitochondrial sequences. Cladistics 21: 209-239.

Burger, A. E. and Williams, A. J. (1979) Egg temperatures of the rockhopper penguin and some other penguins. The Auk 96: 100-105. Catry, I., Alcazar, R., Franco, A. M. A. and Sutherland, W. J. (2009) Identifying the effectiveness and constraints of conservation 
interventions: A case study of the endangered lesser kestrel. Biol. Conserv. 142: 2782-2791.

Catry, I., Franco, A. M. A. and Sutherland, W. J. (2011) Adapting conservation efforts to face climate change: Modifying nest-site provisioning for lesser kestrels. Biol. Conserv. 144: IIII-III9.

Charter, M., Meyrom, K. Leshem, Y., Aviel, S., Izhaki, I. and Motro, Y. (2010) Does nest box location and orientation affect occupation rate and breeding success of barn owls Tyto alba in a semi-arid environment? Acta Ornithol. 45: 115-119.

Crawford, R. J. M., Williams, A. J., Hofmeyer, J. H., Klages, N. T. W., Randall, R. M., Cooper, J., Dyer, B. M. and Chesselet, Y. (1995) Trends of African Penguin Spheniscus demersus populations in the 2oth century. S. Afr. J. Mar. Sci. 16: 101-118.

Crawford, R. J. M., Altwegg, R.., Barham, B. J., Barham, P. J., Durant, J. M., Dyer, B. M. Makhado, A. B., Pichegru, L., Ryan, P. G., Underhill, L. G., Upfold, L., Visagie, J., Waller, L. J. and Whittington, P. A. (2011) Collapse of South Africa's penguins in the early 21st century: a consideration of food availability. Afr. J. Mar. Sci. 33: 139-156.

Davenport, J. (1992) Animal life at low temperature. London: Chapman and Hall.

Dawson, W. R. and Whittow, G. C. (2000) Regulation of body temperature. Pp 343-390 in G. C. Whittow, ed. Avian physiology. San Diego: Academic Press.

Drent, R. H. and Stonehouse, B. (1971) Thermoregulatory responses of the Peruvian penguin, Spheniscus humboldti. Comp. Biochem. Physiol. Part A 40: 689-710.

Durant, S. E., Hepp, G. R., Moore, I. T. and Hopkins, W. A. (2010) Slight changes in incubation temperature affect adrenocortical responsiveness, growth and body condition of wood ducks. J. Exp. Biol. 213: 45-51.

Frere, E., Gandini, P. A. and Boersma, P. D. (1992) Effects of nest type and location on reproductive success of the Magellanic Penguin Spheniscus magellanicus. Mar. Ornithol. 20: 1-6.

Frost, P. G. H., Siegfried, W. R. and Burger, A. E. (1976) Behavioral adaptations of the jackass penguin Spheniscus demersus to a hot, arid environment. J. Zool. 179: 165-187.
Garcia-Navas, V., Arroyo, L., Sanz, J. J. and Diaz, M. (2008) Effect of nest box type on occupancy and breeding biology of tree sparrows Passer montanus in central Spain. Ibis 150: 356-364.

Hockey, P. A. R., Dean, W. R. J. and Ryan, P. G. (2005) Roberts birds of Southern Africa. 7 th edition. Cape Town: John Voelcker Bird Book Fund.

Kemper, J. (2006) Heading toward extinction? Demography of the African Penguin in Namibia. PhD thesis, University of Cape Town, South Africa.

Kemper, J., Underhill, L. G. and Roux, J. P. (2007) Artificial burrows for African Penguins at Halifax Island: do they improve breeding success? Pp. 101-106 in S. P. Kirkman, ed. Final report of the BCLME (Benguela Current Large Marine Ecosystem) project on top predators as biological indicators of ecosystem change in the BCLME. Cape Town, South Africa: Avian Demography Unit.

IUCN (2012) IUCN Red List of Threatened Species. Version 2011.2. www.iucnredlist.org. Libois, E., Gimenez, O., Oro, D., Minguez, E., Pradel, R. and Sanz-Aguilar, A. (2012) Nest boxes: a successful management tool for the conservation of an endangered seabird. Biol. Conserv. 155: 39-43.

Luna-Jorquera, G. (1996) Balancing the energy budget for a warm-blooded bird in a hot desert and cold seas. The case of the Humboldt penguin. PhD thesis, Christian-AlbrechtsUniversitat, Kiel, Gernany.

Lustick, S. (1984) Thermoregulation in adult seabirds. Pp. 183-200 in G. C. Whittow, ed. Seabird energetics New York: Plenum.

Mayfield, H. (1975) Suggestions for calculating nest success. Wilson Bull. 87: 456-466.

Parmesan, C., Root, T. L. and Willig, M. R. (2000) Impacts of extreme weather and climate on terrestrial biota. Bull. Amer. Meteorol. Soc. 81: 443-450.

Perriman, N, L. and Steen, H. (2000) Blue penguin (Eudyptula minor) nest distribution and breeding success on Otago Peninsula, 1992 to 1998. New Zeal. J. Zool. 27: 269-275.

Pichegru, L. (2013) Increasing breeding success of an Endangered penguin: artificial nests or culling predatory gulls? Bird Conserv. Internatn. 23: 296-308. 
R Development Core Team (2010) R: A language and environment for statistical computing. Vienna, Austria: R Foundation for Statistical Computing. http://www.Rproject.org.

Randall, R. M., Randall, B. M. and Erasmus, T. (1986) Rain-related breeding failures in Jackass penguins. Le Gerfaut 76: 281-288.

Renner, M., and Davis, L. S. (2001) Survival analysis of Little Penguin Eudyptula minor chicks on Montuara Island, New Zealand. Ibis 143: 369-379.

Ropert-Coudert, Y., Cannell, B. and Kato, A. (2004) Temperature inside nest boxes of little penguins. Wildl. Soc. Bull. 32: 177-182.

Seddon, P. J. and Davis, L. S. (1989) Nest site selection by yellow-eyed penguins. Condor 91: 653-659.

Shaw, K. A., Waller, L. J., Crawford, R. J. M. and Oosthuizen, W. H. (2012) Draft Biodiversity Management Plan for the African Penguin Spheniscus demersus. Pages 1-72.
Sherley, R., Barham, B., Barham, P., Leshoro, M. and Underhill, L. (2012) Artificial nests enhance the breeding productivity of African Penguins (Spheniscus demersus) on Robben Island, South Africa. Emu 112: 97-106.

Sutherland, W. J., Pullin, A. S., Dolman, P. M. and Knight, T. M. (2004) The need for evidence-based conservation. TREE 19: 305-308.

Urquhart, C. and Klages, N. (1996) East of the Isles. The story of the bird islands of Algoa Bay, South Africa. Bridgemeade, South Africa: Bluecliff Publishing.

Yom-Tov, Y., Wilson, R. P. and Amos, A. R. (1986) Water loss from Jackass Penguin Spheniscus demersus eggs during natural incubation. Ibis 128: $1-8$.

Yorio, P. and Boersma, P. D. (1994) Consequences of nest desertion and inattendance for Magellanic penguin hatching success. Auk 111: 215-218.

\section{BONNIE R. LEI}

Percy FitzPatrick Institute of African Ornithology, DST/NRF Centre of Excellence, University of Cape Town, Private Bag $X_{3}$, Rondebosch 7701, South Africa.

Department of Organismic and Evolutionary Biology, Harvard University, 26 Oxford Street, Cambridge, MA 02138 , USA.

\section{JONATHAN A. GREEN}

School of Environmental Sciences, University of Liverpool, L69 3GP, UK.

\section{LORIEN PICHEGRU*}

DST/NRF Centre of Excellence at the Percy FitzPatrick Institute, Department of Zoology, Nelson Mandela Metropolitan University, Port Elizabeth, South Africa.

Seabird Division, BirdLife South Africa, PO Box 515, Randburg 2125, South Africa.

*Author for correspondence; email: lorien.pichegru@uct.ac.za

Received 16 July 2013; revision accepted 12 December 2013;

Published online 24 February 2014 